\title{
Altered circulating Tregs and their functional cytokines in hypertensive patients with or without left ventricular hypertrophy
}

\section{Ying Tang}

Central South University

\section{Li Shen}

Second Xiangya Hospital

Danyan Xu ( $\nabla$ xudanyan02@csu.edu.cn )

Central South University https://orcid.org/0000-0003-2113-0800

Jing-hui Bao

second Xiangya Hospital Central South University

Original investigation

Keywords: hypertension, left ventricular hypertrophy, Tregs, IL-10, IL-6, TGF- $\beta 1$

Posted Date: August 30th, 2021

DOI: https://doi.org/10.21203/rs.3.rs-847306/v1

License: (c) (i) This work is licensed under a Creative Commons Attribution 4.0 International License. Read Full License 


\section{Abstract}

Background:

Left ventricular hypertrophy $(\mathrm{LVH})$ is the most common target organ damage in hypertension. In addition to the increased left ventricular afterload, immune injury participates in LVH pathogenesis.

$\mathrm{CD} 4^{+} \mathrm{CD} 25^{+} \mathrm{Foxp}^{+}$regulatory $\mathrm{T}$ lymphocytes (Tregs) are a T cell subset with immunomodulatory effects; abnormal Treg numbers or functions can cause immune disorders. This study aimed to explore the role of Tregs in LVH by investigating circulating Tregs and associated cytokine levels in hypertensive patients with LVH.

Methods:

Blood samples were collected from 69 healthy individuals (control group, CG), 91 hypertensive patients with LVH (LVH group) and 83 hypertensive patients without LVH (essential hypertension, EH group). Circulating Tregs and associated cytokines were measured by flow cytometry and enzyme-linked immunosorbent assays, respectively.

Results:

Circulating Tregs were significantly lower in EH and LVH patients than in CG subjects. The circulating Treg level was lower in LVH patients than in EH patients. No correlation between blood pressure regulation and Treg levels was found in EH or LVH patients. Furthermore, circulating Tregs in postmenopausal females were lower than those in males among LVH patients. Additionally, serum IL-10 and transforming growth factor (TGF)- $\beta 1$ were decreased in $\mathrm{EH}$ and LVH patients, and the serum IL- 6 level was significantly increased in LVH patients. Circulating Tregs were negatively correlated with CK, LDL, apoB, high-sensitivity C-reactive protein and left ventricular mass index values.

Conclusion:

Our study is the first to demonstrate the significantly decreased circulating Treg proportion in LVH patients. The protective effect of Tregs in LVH is independent of blood pressure regulation. The functional Treg cytokines IL-6, IL-10 and TGF- $\beta 1$ participate in this immunomodulatory process.

Trial registration:

The study was approved by the Institutional Medical Ethics Committee of the Second Xiangya Hospital of Central South University (2018/No.046).

\section{Background}

Left ventricular hypertrophy ( $\mathrm{LVH})$ is the compensatory response of the left ventricle to the increased cardiac afterload in hypertension. LVH is an independent risk factor associated with adverse outcomes, 
including myocardial infarction, heart failure and sudden death [1, 2]. It is worth noting that LVH persists in hypertensive patients even after the application of antihypertensive drugs to control blood pressure, suggesting that LVH is not just a mechanical adaptation caused by the increase in the afterload. Several studies have demonstrated that inflammation and immunoregulation are essential in pressure overloadinduced LVH that occurs in response to hypertension [3, 4]. Mice that lack lymphocyte responses have a reduced hypertensive response to chronic Ang II infusion and accordingly develop less LVH [5]. This indicates that T cells participate in the onset of Ang II-induced hypertension and LVH.

$\mathrm{CD} 4^{+} \mathrm{CD} 25^{+} \mathrm{Foxp}^{+}{ }^{+}$regulatory $\mathrm{T}$ lymphocytes (Tregs), potent suppressors of effector $\mathrm{T}$ cells, can negatively regulate immune responses, thereby maintaining immune homeostasis and immunologic selftolerance [6]. Decreased proportions of Tregs were observed in the renal cortex of Angll-infused mice [7] and in the peripheral blood and spleen of stroke-prone spontaneously hypertensive rats (SHRs) [8] even before the onset of hypertension. Furthermore, approaches that increase circulating Treg levels in vivo, such as adoptive transfer of Tregs and administration of an IL-2/anti-IL-2 monoclonal antibody complex, were shown to effectively reduce blood pressure in animals with hypertension [7-10]. In addition to Tregs regulating the onset and progression of hypertension, Treg depletion can promote LVH in SHRs [8]. Administration of the IL-2/anti-IL-2 monoclonal antibody complex before transverse aortic constriction was found to attenuate the development of LVH in mice [11]. In addition, adoptive transfer of Tregs reduced LVH without affecting blood pressure in Angll-infused mice [12]. Thus, attenuation of LVH by Treg transfer may be attributed to not only a decrease in blood pressure but also immunosuppressive effects independent of blood pressure regulation.

Tregs exert immunosuppressive effects mainly through the secretion of several anti-inflammatory cytokines, including transforming growth factor (TGF)- $\beta 1$ and IL-10 [6]. Recent studies have confirmed that IL-10 secreted by Tregs plays vital roles in preventing hypertension [13]. Another cytokine, IL-6, can regulate immune homeostasis between T helper 17 (Th17) cells and Tregs. In hypertensive patients, increased circulating IL- 6 can block the TGF- $\beta 1$-mediated generation of Tregs and enhance Th17 responses [14-17], indicating that IL-6 can negatively regulate the effects of Tregs.

LVH is quite common in patients with hypertension. Previous studies have found that Tregs are involved in the progression of hypertension and LVH in different animal models and that the levels of circulating cytokines are altered in hypertension. However, the levels of circulating Tregs and related cytokines in human LVH remain unknown. Our study aimed to investigate Tregs and the associated functional cytokines in hypertensive patients with or without LVH and may offer new insight into immunotherapy for LVH.

\section{Materials And Methods \\ 2.1. Ethics statement}


This study protocol was approved by the Institutional Medical Ethics Committee of the Second Xiangya Hospital of Central South University. The patients themselves or their families provided informed consent.

\subsection{Subjects}

Study subjects were randomly selected from hospitalized patients in the cardiology department and healthy people at the physical examination center of the Second Xiangya Hospital of Central South University from October 2018 to December 2019. In total, 243 patients were included in this study. They were divided into a control group (CG, $n=69)$, essential hypertension $(E H)$ group $(n=83)$, and LVH group $(n=91)$.

\subsection{Reagents and materials}

\subsubsection{Flow cytometry}

Isolated cell suspensions were stained for fluorescence-activated cell sorting (FACS) analysis using the following antibodies: fluorescein isothiocyanate (FITC)-conjugated anti-human CD4 (clone SK3), phycoerythrin (PE)-conjugated anti-human Foxp3 (clone 206D), and allophycocyanin (APC)-conjugated anti-human CD25 (clone BC96) (all from BioLegend). samples were analyzed on a CytoFLEX (Beckman Coulter). Data were analyzed with FlowJo software.

\subsubsection{Cytokine assays}

Peripheral blood samples were collected using a coagulant. The serum concentrations of IL-10, IL-6 and TGF- $\beta 1$ were measured using enzyme-linked immunosorbent assay (ELISA) kits according to the manufacturer's instructions.

\subsection{Standards for the study subjects}

\subsubsection{Diagnostic criteria for the study subjects}

All included subjects had satisfactory echocardiogram results (Mindray DC-8). The left ventricular enddiastolic diameter (LVEDd), interventricular septal diameter (IVSd), and posterior wall thickness (PWT) were measured. Left ventricular (LV) mass in grams was calculated according to the following formula [18]: LV mass $(g)=0.8 \times 1.04 \times\left[\left(\text { LVEDd }^{2} \text { IVSd + PWT }\right)^{3}\right.$-LVEDd $\left.{ }^{3}\right]+0.6$. LV mass was indexed to body surface area and is reported in $\mathrm{g} / \mathrm{m}^{2}$ : LV mass index $(\mathrm{LVMI})=\mathrm{LV}$ mass / body surface area.

The diagnostic criteria for hypertension were as follows: 1) systolic blood pressure (SBP) $\geq 140 \mathrm{mmHg}$ and/or diastolic blood pressure (DBP) $\geq 90 \mathrm{mmHg}$; and/or 2) a history of hypertension with current use of antihypertensive drugs to reduce the blood pressure below $140 / 90 \mathrm{mmHg}$, referring to the Guidelines for Prevention and Treatment of Hypertension in China (2018 edition) [19].

The diagnostic criteria for $\mathrm{LVH}$ were an $\mathrm{LVMI} \geq 115 \mathrm{~g} / \mathrm{m}^{2}$ for males and $\geq 95 \mathrm{~g} / \mathrm{m}^{2}$ for females [20]. 


\subsubsection{Inclusion and exclusion criteria for the research subjects}

The inclusion criteria for the study subjects were as follows:

1. Between the ages of $25-80$ years old (CG, EH, and LVH groups);

2. In line with the diagnostic criteria for hypertension (EH and LVH groups); and

3. In line with the diagnostic criteria for LVH (LVH group).

The exclusion criteria for the study subjects were as follows:

1. Secondary hypertension;

2. Valvular heart disease, myocarditis, congenital heart disease, severe arrhythmia, or congestive heart failure;

3. Acute and chronic inflammation of the heart or other organs;

4. Abnormal liver and/or kidney function;

5. Malignant tumors or other immune diseases, such as rheumatism;

6. Lung diseases that seriously affect respiratory function;

7. High fever or use of immunomodulatory drugs; and

8. Ongoing pregnancy or breastfeeding.

\subsection{Statistical analysis}

IBM SPSS 25.0 software (SPSS Inc., Chicago, USA) was used to analyze all the data. Enumeration data were analyzed using the $\mathrm{X}^{2}$ test, and the results are presented as the constituent ratio. Measurement data are presented as the mean \pm standard deviation $(M \pm S D)$. Kolmogorov-Smirnov normality tests were conducted for all measurement data. Comparisons among groups with normally distributed data were performed using ANOVA with the least significant difference (LSD) test as the post hoc test. Comparisons between groups with nonnormally distributed data were performed using the Kruskal-Wallis rank-sum test with the Mann-Whitney U test. Pearson's and Spearman's correlation analyses were used to calculate correlations between two variables. A two-tailed value of $p<0.05$ was considered statistically significant.

\section{Results}

\subsection{Basic clinical characteristics of patients}

Among the patients who provided blood samples for analysis, body weight, body mass index (BMI), incidence rate of smoking, and blood pressure (including SBP and DBP) were significantly increased in the EH and LVH groups compared with the CG group (all $P<0.05$ ), indicating possible roles of these comorbidities in the pathogenesis of EH and LVH. SBP was higher in the LVH group than in the EH group $(P<0.05)$. No significant differences in other characteristics, including age, body weight, BMI, incidence 
rate of smoking, and DBP, were found between the EH and LVH groups (all $P>0.05$ ). The clinical data of all patients are listed in Table 1.

Table 1

Information of clinical characteristics in CG, EH and LVH groups

\begin{tabular}{|llll|}
\hline Characteristics & CG & EH & LVH \\
\hline Gender $(\mathrm{M} / \mathrm{F})$ & $45 / 24$ & $55 / 28$ & $59 / 32$ \\
\hline Age (years) & $58.45 \pm 12.86$ & $58.30 \pm 10.88$ & $61.34 \pm 11.17$ \\
\hline Height $(\mathrm{cm})$ & $162.34 \pm 7.92$ & $163.06 \pm 7.19$ & $163.86 \pm 8.78$ \\
\hline Weight $(\mathrm{kg})$ & $60.58 \pm 11.43$ & $67.91 \pm 11.18^{*}$ & $69.91 \pm 14.08^{*}$ \\
\hline BMI $\left(\mathrm{kg} / \mathrm{m}^{2}\right)$ & $22.86 \pm 3.12$ & $25.47 \pm 3.30^{*}$ & $25.88 \pm 3.90^{\star}$ \\
\hline SBP $(\mathrm{mm} \mathrm{Hg})$ & $122.41 \pm 16.19$ & $141.30 \pm 17.75^{*}$ & $148.40 \pm 23.68^{\star}$ \\
\hline DBP $(\mathrm{mm} \mathrm{Hg})$ & $78.45 \pm 9.18$ & $85.25 \pm 13.01^{*}$ & $87.01 \pm 15.74^{*}$ \\
\hline Smoking $(\mathrm{n}, \%)$ & $18(26.09 \%)$ & $40(48.2 \%)^{*}$ & $43(47.3 \%)^{*}$ \\
\hline
\end{tabular}

Compared with the CG group, the EH group did not show any significant differences in the white blood cell count (WBC), neutrophil percentage (N\%), high-sensitivity C-reactive protein (hs-CRP) or N-terminal brain natriuretic peptide (NT-proBNP) (all $P>0.05$ ). However, these characteristics were increased in the LVH group compared with the CG group (all $P<0.05$ ), indicating upregulated inflammation in the LVH patients. The level of NT-proBNP was higher in the LVH group than in the EH group $(P<0.05)$, but no significant differences in the WBC, N\% or hs-CRP level were found (all $P>0.05$ ) (Table 2). 
Table 2

Information of blood biochemical indexes in CG, EH and LVH groups

\begin{tabular}{|c|c|c|c|}
\hline Indexes & CG & EH & LVH \\
\hline WBC $\left(\times 10^{9} / \mathrm{L}\right)$ & $6.10 \pm 1.37$ & $6.53 \pm 1.57$ & $6.68 \pm 1.66^{*}$ \\
\hline$N(\%)$ & $61.04 \pm 9.33$ & $63.84 \pm 7.84$ & $64.79 \pm 9.23^{*}$ \\
\hline hs-CRP (mg/dL) & $1.43 \pm 2.37$ & $3.99 \pm 7.34$ & $6.01 \pm 14.30^{*}$ \\
\hline NT-proBNP (pg/ml) & $162.16 \pm 196.15$ & $165.76 \pm 231.22$ & $624.93 \pm 1114.08^{\star \#}$ \\
\hline $\operatorname{cTnT}(\mu \mathrm{g} / \mathrm{L})$ & $8.96 \pm 16.83$ & $35.36 \pm 160.69$ & $38.49 \pm 82.31$ \\
\hline CK (pg/ml) & $79.73 \pm 29.54$ & $96.37 \pm 48.34$ & $86.52 \pm 42.00$ \\
\hline CK-MB (pg/ml) & $15.51 \pm 10.96$ & $16.20 \pm 8.48$ & $15.97 \pm 10.02$ \\
\hline TG (mmol/L) & $1.53 \pm 1.09$ & $2.19 \pm 1.45^{\star}$ & $2.04 \pm 1.75$ \\
\hline $\mathrm{TC}(\mathrm{mmol} / \mathrm{L})$ & $4.41 \pm 0.97$ & $4.03 \pm 0.94^{\star}$ & $3.94 \pm 0.98^{*}$ \\
\hline $\mathrm{HDL}-\mathrm{C}(\mathrm{mmol} / \mathrm{L})$ & $1.09 \pm 0.36$ & $0.95 \pm 0.28^{\star}$ & $0.96 \pm 0.21^{*}$ \\
\hline LDL-C (mmol/L) & $2.78 \pm 0.83$ & $2.51 \pm 0.76$ & $2.42 \pm 0.85^{\star}$ \\
\hline HDL-C/TC & $0.26 \pm 0.10$ & $0.24 \pm 0.07$ & $0.26 \pm 0.08$ \\
\hline $\mathrm{FFA}(\mathrm{mmol} / \mathrm{L})$ & $0.29 \pm 0.19$ & $0.34 \pm 0.17$ & $0.37 \pm 0.18^{\star}$ \\
\hline $\mathrm{Lp}(\mathrm{a})(\mathrm{mg} / \mathrm{L})$ & $131.14 \pm 129.80$ & $310.39 \pm 296.31^{*}$ & $332.30 \pm 265.49^{\star}$ \\
\hline apoA (g/L) & $1.07 \pm 0.25$ & $0.98 \pm 0.21$ & $0.98 \pm 0.19$ \\
\hline apoB (g/L) & $0.89 \pm 0.27$ & $0.82 \pm 0.22$ & $0.79 \pm 0.25^{*}$ \\
\hline $\mathrm{HbA1c}(\%)$ & $5.41 \pm 0.28$ & $6.54 \pm 1.29^{\star}$ & $6.81 \pm 1.13^{\star \#}$ \\
\hline
\end{tabular}

In addition, no significant differences were observed among the three groups for myocardial enzymological indexes, including cardiac troponin T (cTnT), creatine kinase (CK) and an isoenzyme of creatine kinase-MB (CK-MB) (all $P>0.05$ ) (Table 2).

Compared with the CG group, the EH group exhibited increased triglycerides (TG), and the LVH group showed increased free fatty acids (FFA) (all $P<0.05)$. Total cholesterol (TC) was lower while lipoprotein (a) $(\mathrm{Lp}(\mathrm{a}))$ was higher in the EH and LVH groups than in the CG group, and low-density lipoprotein cholesterol (LDL-C) and apoprotein B (apoB) were lower in the LVH group than in the CG group (all $P<$ 0.05). High-density lipoprotein cholesterol (HDL-C) was lower in the EH and LVH groups than in the CG group (all $P<0.05$ ), but there were no differences in apoprotein $\mathrm{A}$ (apoA) or the HDL-C/TC ratio among the three groups (all $P>0.05$ ) (Table 2). 
Compared with the CG group, the EH and LVH groups showed increased levels of glycosylated hemoglobin A1 (HbA1c) (all $P<0.05)$. The level of HbA1c was much higher in $\mathrm{LVH}$ patients than in $\mathrm{EH}$ patients $(P<0.05)$ (Table 2$)$.

\subsection{Analysis of patient echocardiograms}

The left atrium (LA) was increased in the EH group compared with the CG group $(P<0.05)$. Compared with the CG and EH groups, the LVH group showed higher LA and right atrium (RA) values (all $P<0.05$ ).

The IVSd, PWT and LVMI were increased in the EH group compared with the CG group (all $P<0.05$ ). Additionally, compared with the CG and EH groups, the LVH group showed higher LVEDd, IVSd, PWT and LVMI values (all $P<0.05$ ).

In addition, the ejection fractions (EF) of the three groups were in the normal range (50-70\%), but the EF in the LVH and EH groups were both decreased compared with that in the CG group, and the EF was lower in the LVH group than in the EH group (all $P<0.05$ ). These data are listed in Table 3.

Table 3

Characteristics of echocardiogram in CG, EH and LVH groups

\begin{tabular}{|llll|}
\hline Characteristics & CG & EH & LVH \\
\hline IVSd $(\mathrm{mm})$ & $8.95 \pm 1.01$ & $10.11 \pm 1.00^{*}$ & $11.56 \pm 1.41^{\text {*\# }}$ \\
\hline PWT $(\mathrm{mm})$ & $8.74 \pm 0.96$ & $9.41 \pm 0.90^{\star}$ & $10.97 \pm 1.34^{\star \#}$ \\
\hline LVEDd $(\mathrm{mm})$ & $45.43 \pm 4.37$ & $46.18 \pm 3.09$ & $50.54 \pm 4.18^{\star \#}$ \\
\hline LVMI (g/m²) & $93.92 \pm 19.13$ & $105.11 \pm 12.16^{*}$ & $148.70 \pm 21.41^{\star \#}$ \\
\hline LA (mm) & $31.38 \pm 3.35$ & $34.80 \pm 3.91^{*}$ & $38.02 \pm 3.85^{\star \#}$ \\
\hline RA (mm) & $31.05 \pm 3.09$ & $30.89 \pm 2.98$ & $32.36 \pm 3.20^{* \#}$ \\
\hline RV (mm) & $29.86 \pm 3.60$ & $30.18 \pm 2.85$ & $30.98 \pm 3.04$ \\
\hline EF (\%) & $63.93 \pm 4.76$ & $62.30 \pm 3.69^{*}$ & $57.80 \pm 7.98^{* \#}$ \\
\hline
\end{tabular}

\subsection{Circulating $\mathrm{CD}^{+} \mathrm{T}$ cells and Tregs in patients}

The levels of circulating $\mathrm{CD} 4^{+} \mathrm{T}$ cells and Tregs were analyzed by flow cytometry, and the results showed that circulating $\mathrm{CD}^{+} \mathrm{T}$ cells were similar among the CG (41.66 $\left.\pm 8.54 \%\right), \mathrm{EH}(42.34 \pm 8.03 \%)$ and LVH $(41.14 \pm 9.11 \%)$ groups $(P>0.05)$ (Fig. 1(a), 1(b)). Compared with the levels in the CG group (5.17 \pm $2.16 \%)$, the Treg levels in the $\mathrm{EH}(4.29 \pm 1.86 \%)$ and LVH group $(3.68 \pm 1.51 \%)$ were significantly decreased (Fig. 1(a) and 1(c)), and the Treg level was lower in LVH patients than in EH patients (all $P<$ 0.05) (Table 4). 
Table 4

Tregs and serum cytokine levels in CG, EH and LVH groups

\begin{tabular}{|llll|}
\hline Characteristics & CG & EH & LVH \\
\hline Treg $(\%)$ & $5.17(4.43-5.91)$ & $4.29(3.86-4.72)^{*}$ & $3.68(3.35-4.02))^{* \star *}$ \\
\hline IL-10 $(\mathrm{pg} / \mathrm{ml})$ & $9.14(6.92-11.36)$ & $6.12(4.52-7.72){ }^{*}$ & $6.11(4.67-7.56){ }^{*}$ \\
\hline TGF- $\beta 1(\mathrm{ng} / \mathrm{ml})$ & $42.92(39.46-46.38)$ & $37.73(33.61-41.84)^{*}$ & $37.09(33.68-40.49)$ \\
\hline IL-6 (pg/ml) & $6.52(3.67-9.38)$ & $7.45(4.77-10.12)$ & $11.54(8.10-14.99)$
\end{tabular}

\subsection{Correlation between blood pressure control and circulating Tregs in hypertensive patients}

Blood pressure control is closely related to the occurrence of hypertensive myocardial hypertrophy. To explore whether the decreased level of Tregs in hypertensive patients is affected by blood pressure regulation, the $\mathrm{EH}$ and $\mathrm{LVH}$ groups were further divided into well-controlled and poorly controlled groups according to each patient's blood pressure control situation (24-hour ambulatory blood pressure was measured). The well-controlled group was defined by a mean SBP $<140 \mathrm{mmHg}$ and mean DBP $<90$ $\mathrm{mmHg}$, while the poorly controlled group was defined by a mean SBP $\geq 140 \mathrm{mmHg}$ and/or mean DBP $\geq$ $90 \mathrm{mmHg}$. The results showed no difference in Treg levels between the well-controlled and poorly controlled subgroups in either EH patients or LVH patients (all $P>0.05$ ) (Fig. 2(a)). Moreover, no correlation was found between Tregs and the duration of hypertension in LVH patients $(P>0.05)$ (Fig. 2(b)). These results reveal that there is no correlation between blood pressure control and circulating Treg levels in hypertensive patients.

\subsection{Circulating Tregs in male and female hypertensive patients}

In the EH and LVH groups, we further compared the proportion of circulating Tregs between male and female patients, but no sex difference in circulating Tregs was found $(P>0.05)$ (Fig. 3). Several studies have revealed that estrogen could protect the murine heart from pressure overload-induced LVH [21-23]. Considering the possible role of estrogen in attenuating LVH, we compared the Treg levels in hypertensive patients between males ( $>49$ years old) and postmenopausal females aged over 49 years old (the median age at onset of menopause in Asia) [24].

The results showed that circulating Tregs were lower in postmenopausal females than in males (>49 years old) in both the LVH and EH groups (all $P<0.05$ ) (Fig. 3), indicating that Tregs may participate in the modulatory mechanism through which estrogen protects female patients from hypertension and LVH. In addition, in postmenopausal females, circulating Treg levels were still lower in the LVH group than in the EH group $(P<0.05)$, indicating that decreased circulating Treg levels may participate in the onset of $\mathrm{LVH}$ in hypertensive patients even without the effect of estrogen. 


\subsection{Serum cytokine concentrations in patients}

To investigate the expression of functional cytokines related to Tregs, serum IL-10, IL-6, and TGF- $\beta 1$ levels were measured by ELISA. Decreased IL-10 and TGF- $\beta 1$ concentrations were observed in the EH and LVH groups compared with the CG group (all $P<0.05$ ) (Fig. 4(a-b) and Table 4); no significant differences were observed between the EH and LVH groups for these cytokines (all $P>0.05$ ). The serum IL-6 level was increased in the LVH group compared with the EH and CG groups (all $P<0.05$ ) (Fig. 4(c) and Table 4). No significant difference in IL-6 was found between the EH and CG groups $(P>0.05)$.

We then assessed whether the level of circulating Tregs was associated with functional cytokines in the serum in CG, EH and LVH patients, and correlation analysis showed that circulating Tregs were negatively correlated with the serum concentration of IL-10 and positively correlated with the serum concentration of TGF- $\beta 1$ in LVH patients (all $P<0.05$ ). No correlation was found between Tregs and serum IL-6 among the three groups (all $P>0.05$ ) (Fig. 4(d-f)).

\subsection{Associations between circulating Tregs and clinical characteristics}

We assessed whether circulating Tregs were associated with the clinical characteristics of all 243 individuals. Correlation analysis showed that circulating Tregs were negatively correlated with LVMI, hsCRP and CK levels (all $P<0.05$ ) but not with age, smoking index, BMI, SBP, DBP, WBC, HbA1c, NT-proBNP, cTnT, CK, CK-MB, TC, TG, HDL-C, LDL-C, Lp(a), apoA, or apoB levels (all $P>0.05$ ) (Table 5 and Fig. 5(a-c)). In addition, circulating Tregs were negatively correlated with CK, LDL and apoB in EH patients (all $P<$ $0.05)$ (Table 6 and Fig. 5(d-f)). In the LVH group, circulating Tregs were negatively correlated with $\mathrm{CK}(P<$ 0.05) (Table 7 and Fig. 5(g)). 
Table 5

Correlations between Tregs and clinical characteristics were assessed by

Pearson and Spearman's correlation analysis in total 243 patients.

\begin{tabular}{|lll|}
\hline Characteristics & R & P value \\
\hline Age & -0.0313 & 0.646 \\
\hline BMI & 0.092 & 0.178 \\
\hline Smoking index & 0.0688 & 0.312 \\
\hline LVMI & -0.1632 & $0.025^{\star}$ \\
\hline SBP & 0.0083 & 0.903 \\
\hline DBP & -0.0150 & 0.825 \\
\hline WBC & 0.1262 & 0.064 \\
\hline hs-CRP & -0.1520 & $0.049^{\star}$ \\
\hline cTnT & -0.0634 & 0.393 \\
\hline CK & -0.1909 & $0.011^{\star}$ \\
\hline CK-MB & -0.1040 & 0.139 \\
\hline NT-proBNP & 0.0600 & 0.402 \\
\hline Lp(a) & -0.1278 & 0.085 \\
\hline HbA1c & 0.0090 & 0.922 \\
\hline TG & -0.0378 & 0.588 \\
\hline TC & 0.0309 & 0.658 \\
\hline HDL-C & -0.107 & 0.123 \\
\hline LDL-C & 0.0598 & 0.392 \\
\hline apoA & -0.0260 & 0.727 \\
\hline apoB & 0.0716 & 0.334 \\
\hline
\end{tabular}


Table 6

Correlations between Tregs and clinical characteristics were assessed by Pearson and Spearman's correlation analysis in EH patients.

\begin{tabular}{|lll|}
\hline Characteristics & R & P value \\
\hline CK $(\mathrm{pg} / \mathrm{ml})$ & -0.2621 & $0.028^{*}$ \\
\hline LDL-C $(\mathrm{mmol} / \mathrm{L})$ & -0.2394 & $0.041^{*}$ \\
\hline ApoB $(\mathrm{g} / \mathrm{L})$ & -0.2398 & $0.046^{*}$ \\
\hline
\end{tabular}

Table 7

Correlations between Tregs and CK was assessed by Pearson's correlation analysis in LVH patients.

\begin{tabular}{|lll|}
\hline Characteristic & $\mathbf{R}$ & P value \\
\hline $\mathrm{CK}(\mathrm{pg} / \mathrm{ml})$ & -0.2587 & $0.014^{*}$ \\
\hline
\end{tabular}

\section{Discussion}

In the present study, we observed for the first time that circulating Treg levels were decreased in patients with hypertensive myocardial hypertrophy compared with hypertensive patients without LVH. The Treg level was independent of the blood pressure control status. Among hypertensive patients, the circulating Treg level in postmenopausal females was lower than that in males. We also are the first to observe that serum IL-6 levels were increased in hypertensive patients with LVH compared with those without LVH. In addition, the serum levels of the anti-inflammatory cytokines IL-10 and TGF- $\beta 1$ were decreased in hypertensive patients. In addition, circulating Tregs were positively correlated with the levels of TGF- $\beta 1$ and negatively correlated with those of CK, hs-CRP, LVMI, LDL and apoB.

Endothelial cells are a vital regulator of vascular tone, and endothelial dysfunction serves as an initiating factor of hypertension. Impaired endothelium-dependent relaxation of the arteries has been found in both hypertensive patients and animal models [25]. Endothelial function can be protected by Tregs [26], whereas a decreased proportion of Tregs can induce endothelial dysfunction and initiate the onset of hypertension [27, 28]. Mice infused with aldosterone or Ang II were found to show endothelial dysfunction, adverse vascular remodeling and elevated SBP, whereas these pathologic processes could be effectively attenuated by adoptive transfer of Tregs [7, 29].

Tregs comprise $5-10 \%$ of all peripheral $\mathrm{CD} 4^{+} \mathrm{T}$ cells in adults. Although $\mathrm{CD} 4^{+} \mathrm{T}$ cells have no obvious effect on Ang II-induced blood pressure elevation [30], Treg depletion or dysfunction can exacerbate endothelial dysfunction and promote the occurrence of hypertension $[8,27,28]$. Similarly, no significant differences in circulating $\mathrm{CD}^{+} \mathrm{T}$ cells were found among the $\mathrm{CG}$, $\mathrm{EH}$ and $\mathrm{LVH}$ groups in our study, while 
the proportion of circulating Tregs was significantly decreased in patients with hypertension, indicating that the reduced proportion of circulating Tregs might promote the progression of hypertension. Another study revealed that mice treated with Ang II or Ang II + Tregs upregulated Foxp $3^{+}$cell infiltration in the heart [12], indicating that circulating Tregs might be recruited to the heart to inhibit the onset of hypertension. It is possible that the renin-angiotensin system is activated in patients with hypertension and that Ang II activates chemoattractant signaling in the recruitment of Tregs from the circulation to cardiac tissue for accumulation in the early stage of hypertension; therefore, circulating Treg levels are decreased in patients with hypertension.

Hypertension increases the workload of the heart and causes structural or functional changes in the myocardium. These changes include LVH, which can cause an electric remodeling process and further contribute to increased incidences of ventricular arrhythmias and sudden cardiac death. Previous studies have revealed that a decreased proportion of Tregs is crucial for the onset of hypertension and LVH in mice and rats $[8,11,12,28]$. Hypertensive mice treated with Treg transfer develop less LVH and exhibit reduced susceptibility to inducible ventricular tachycardia, accompanied by diminished cardiac cell infiltration and a reduced proportion of activated splenic $\mathrm{CD} 4^{+}$cells [12]. Therefore, Tregs might inhibit LVH and electrical remodeling by inhibiting the activation of immune cells and their migration from peripheral immune organs into the heart. However, these results were all generated with animal models and do not reveal whether the proportion or function of Tregs is altered between LVH and EH patients. In this study, we found that circulating Treg levels were significantly lower in hypertensive patients with LVH than in those without LVH, indicating that decreased circulating Treg levels further facilitate cardiac injury in hypertension.

To explore the correlation between Treg levels and blood pressure regulation, we compared the proportion of Tregs in hypertensive patients according to their blood pressure control condition. The results showed no difference in circulating Tregs between the well-controlled and poorly controlled subgroups. Similarly, mice treated with Ang II + Tregs were found to be as hypertensive as Ang II-treated controls, but cardiac hypertrophy and fibrosis were significantly ameliorated [12]. These findings underscore the notion that Treg-mediated cardiac protection is independent of modulatory effects on blood pressure.

We also explored the sex difference in Tregs in hypertensive patients. We found lower Treg levels in females than in males among hypertensive patients over 49 years old, while no sex difference was found between males and females of all ages. In previous studies, administration of $17 \beta$-estradiol, the main circulating form of estrogen in premenopausal females, limited hypertension and LVH in ovariectomized female mice [22, 23], indicating that estrogen may protect premenopausal females from hypertension and LVH. These results indicate that Tregs may mediate the modulatory effect of estrogen in attenuating EH and LVH.

The protective effect of Tregs on microvascular endothelial function in hypertension may be attributed to the release of Treg-associated anti-inflammatory cytokines, such as TGF- $\beta$ and IL-10, thereby inhibiting NADPH oxidase activity and improving endothelium-dependent relaxation of the arteries [31-33]. We

Page $13 / 25$ 
found for the first time that serum IL-10 and TGF- $\beta 1$ levels were decreased in hypertensive patients with or without $\mathrm{LVH}$, indicating a role for anti-inflammatory cytokines in the development of EH and LVH. In addition, circulating Tregs were positively correlated with the levels of TGF- $\beta 1$ in our study. There were two reasons. First, Tregs can secret TGF- $\beta 1$ [34]. Second, TGF- $\beta 1$ can induce the differentiation of naive T cells into Tregs and thus increase the number of Tregs [35]. TGF- $\beta 1$-deficient mice exhibit a significantly decreased proportion of peripheral Tregs [36]. Therefore, the positive correlation between Tregs and TGF$\beta 1$ is undeniable.

Surprisingly, we found that circulating Tregs were negatively correlated with the serum levels of IL-10. Similarly, Tlili et al. [29] found that adoptive transfer of Tregs normalized the increased level of IL-10 in Ang Il-induced hypertensive mice. They speculated that both Tregs and IL-10 could downregulate the levels of proinflammatory cytokines. After Treg adoptive transfer, feedback loops that modulate proinflammatory cytokines by increasing IL-10 were inhibited, and therefore, the level of IL-10 was decreased. In fact, IL-10 can be produced by multiple cell types, such as neutrophils, dendritic cells (DCs), mast cells, monocytes, macrophages, eosinophils, and natural killer cells, in addition to B cells and CD $8^{+}$ and $\mathrm{CD} 4^{+} \mathrm{T}$ cells [37]. We could not rule out the secretory function of other cells in terms of IL-10. In addition, the infiltration of proinflammatory cytokines may act in different ways between the serum and heart tissue. In our study, circulating Tregs were negatively correlated with serum IL-10, while in another study, cardiac IL-10 was elevated after adoptive transfer of Tregs [38], so serum and cardiac IL-10 may have different correlations with circulating Tregs.

IL- 6 is produced by a variety of cell types, including monocytes, T cells, B cells and endothelial cells. IL-6 signaling is critical for cardiomyocyte hypertrophy and Th17/Treg balance regulation [16]. Cardiac IL-6 expression is increased in pressure-overloaded hearts [39]. Similarly, serum IL-6 was increased in LVH patients in our study. Studies targeting IL-6 further support an essential role for this cytokine as a driver of inflammatory disease mechanisms in animal models of hypertension, preeclampsia, and LVH. In previous studies, IL-6 $6^{-/-}$mice were protected from both Angll-induced hypertension [40, 41] and LVH [42]. Pressure overload-induced LV cardiac remodeling and functional deterioration were shown to be attenuated in the absence of IL-6, indicating an important role for this cytokine in hypertensive myocardial remodeling [42]. In addition, bazedoxifene, a drug for anti-inflammatory therapy, can protect the heart from cardiac remodeling by inhibiting IL-6/gp130 signaling in TAC mice [43]. Thus, IL- 6 may be a potential therapeutic target in LVH.

An increased level of CRP or hs-CRP is closely related to the onset of LVH in patients with hypertension and can be an independent predictor of LVH $[44,45]$. We also found elevated hs-CRP levels in hypertensive patients with LVH compared with hypertensive patients without LVH and healthy individuals, indicating the hyperinflammatory state in patients with LVH and a possible application for hs-CRP in predicting the occurrence of LVH. In addition, the plasma NT-proBNP level was significantly elevated in patients with LVH in our study. Similarly, plasma NT-proBNP has been found to rise progressively with increasing hypertension severity, particularly when LVH is present [46]. In a previous study on Black patients with hypertension, however, even though NT-proBNP was effective in differentiating hypertensive 
subjects with or without LVH from those with hypertensive heart failure, it could not differentiate hypertensive patients with LVH from those without LVH [47]. Therefore, whether NT-proBNP is an ideal marker for LVH is still controversial. The LVMI is commonly used to identify patients with cardiac hypertrophy. We found a negative correlation between circulating Tregs and LVMI values in all 243 subjects, indicating that circulating Tregs may be combined with the LVMI to predict LVH in hypertensive patients. In patients with rheumatic heart disease, Tregs were found to have negative relationship with CK-MB [48]. In this study, we also found a negative correlation between circulating Tregs and serum CK. However, the detailed mechanism of their negative relationship needs to be further explored.

Moreover, dyslipidemia and abnormal blood glucose levels were previously found in hypertensive patients with or without LVH $[49,50]$. Increased body weight, BMI, HbA1c and Lp(a) values as well as a decreased HDL-C level were also found in hypertensive patients in our study. We also found that the proportion of circulating Tregs was negatively related to LDL-C and apoB in patients with hypertension. $L D L$, the shell of which contains apoB-100, can carry cholesterol to form LDL-C. However, oxidized LDL (ox-LDL), not native LDL, can promote cholesterol accumulation in monocytes and macrophages [51]. The Fas/Fas ligand (FasL) pathway in activation-induced cell death serves as the major mechanism of peripheral Treg apoptosis [52], and increased ox-LDL levels may activate Fas/FasL/Caspase-3-mediated Treg apoptosis $[52,53]$. These results may provide clues about the negative correlation between Tregs and LDL-C in hypertension. A negative correlation was previously found between the levels of circulating Tregs and $\mathrm{HbA1c}$ in obese patients [54], while no correlation was found in our study. This may be related to the small number of diabetic patients in our study.

The present study had several limitations. First, macrophages, neutrophils, and other subsets of $\mathrm{CD} 4^{+} \mathrm{T}$ cells were significant inflammatory cells, but we did not detect their proportions. In addition, the 243 patients were all from the Second Xiangya Hospital, so the conclusion has to be verified in a large, multicenter study.

\section{Conclusion}

In conclusion, altered levels of circulating Tregs, IL-10, TGF- $\beta 1$, and IL-6 were found in EH and LVH patients. The morbidity and mortality in patients with LVH were significantly increased, but the current treatment approach for LVH still follows standard hypertension guidelines and has unclear benefits [55]. Our study provides possible molecular targets for immunotherapy for hypertension and hypertensive myocardial hypertrophy. In contrast to the administration of traditional antihypertensive drugs, increasing the proportion of functional Tregs and supplementing anti-inflammatory cytokines or reducing proinflammatory cytokine levels may be new approaches for the treatment of hypertension and LVH.

\section{Declarations}

\section{Availability of data and materials}


The data used in the current study are available upon reasonable request to the corresponding author.

\section{Contributions}

Ying Tang and Li Shen carried out the molecular genetic studies, participated in the sequence alignment and drafted the manuscript. Jing-hui Bao carried out the immunoassays. Ying Tang participated in the sequence alignment. Ying Tang participated in the design of the study and performed the statistical analysis. Dan-yan Xu conceived of the study, and participated in its design and coordination and helped to draft the manuscript. All authors read and approved the final manuscript.

\section{Ethics approval and consent to participate}

This study protocol was approved by the Institutional Medical Ethics Committee of the Second Xiangya Hospital of Central South University (2018/No.046). Written informed consent to participate was acquired from patients themselves or their families.

\section{Consent for publication}

Not applicable.

\section{Competing Interests}

The authors declare that they have no conflicts of interest.

\section{Acknowledgements}

Not applicable.

\section{Funding}

This work was supported by the National Nature Scientific Funding of China (No. 81871858, 82072555, 82172550) and Chinese Cardiovascular Association-Access fund (2019-CCA-ACCESS-023).

\section{References}

1. Virani SS, Alonso A, Benjamin EJ, Bittencourt MS, Callaway CW, Carson AP, Chamberlain AM, Chang AR, Cheng S, Delling FN, et al: Heart Disease and Stroke Statistics-2020 Update: A Report From the American Heart Association. Circulation2020, 141:e139-e596.

2. Yildiz M, Oktay AA, Stewart MH, Milani RV, Ventura HO, Lavie CJ: Left ventricular hypertrophy and hypertension. Prog Cardiovasc Dis2020, 63:10-21.

3. Koyanagi M, Egashira K, Kitamoto S, Ni W, Shimokawa H, Takeya M, Yoshimura T, Takeshita A: Role of monocyte chemoattractant protein-1 in cardiovascular remodeling induced by chronic blockade of nitric oxide synthesis. Circulation2000, 102:2243-2248. 
4. Liu Y, Lu H, Zhang C, Hu J, Xu D: Recent advances in understanding the roles of T cells in pressure overload-induced cardiac hypertrophy and remodeling. J Mol Cell Cardio/2019, 129:293-302.

5. Crowley SD, Song YS, Lin EE, Griffiths R, Kim HS, Ruiz P: Lymphocyte responses exacerbate angiotensin II-dependent hypertension. Am J Physiol Regul Integr Comp Physio/2010, 298:R1089-1097.

6. Sakaguchi S: Naturally arising Foxp3-expressing CD25+CD4+ regulatory T cells in immunological tolerance to self and non-self. Nat Immuno/2005, 6:345-352.

7. Kasal DA, Barhoumi T, Li MW, Yamamoto N, Zdanovich E, Rehman A, Neves MF, Laurant P, Paradis P, Schiffrin EL: T regulatory lymphocytes prevent aldosterone-induced vascular injury. Hypertension2012, 59:324-330.

8. Katsuki M, Hirooka Y, Kishi T, Sunagawa K: Decreased proportion of Foxp3+ CD4+ regulatory T cells contributes to the development of hypertension in genetically hypertensive rats. J Hypertens2015, 33:773783; discussion 783.

9. Viel EC, Lemarié CA, Benkirane K, Paradis P, Schiffrin EL: Immune regulation and vascular inflammation in genetic hypertension. Am J Physiol Heart Circ Physio/2010, 298:H938-944.

10. Cui C, Fan J, Zeng Q, Cai J, Chen Y, Chen Z, Wang W, Li SY, Cui Q, Yang J, et al: CD4(+) T-Cell Endogenous Cystathionine $y$ Lyase-Hydrogen Sulfide Attenuates Hypertension by Sulfhydrating Liver Kinase B1 to Promote T Regulatory Cell Differentiation and Proliferation. Circulation2020, 142:17521769.

11. Wang H, Hou L, Kwak D, Fassett J, Xu X, Chen A, Chen W, Blazar BR, Xu Y, Hall JL, et al: Increasing Regulatory T Cells With Interleukin-2 and Interleukin-2 Antibody Complexes Attenuates Lung Inflammation and Heart Failure Progression. Hypertension2016, 68:114-122.

12. Kvakan H, Kleinewietfeld M, Qadri F, Park JK, Fischer R, Schwarz I, Rahn HP, Plehm R, Wellner M, Elitok S, et al: Regulatory T cells ameliorate angiotensin Il-induced cardiac damage. Circulation2009, 119:29042912.

13. Iulita MF, Duchemin S, Vallerand D, Barhoumi T, Alvarez F, Istomine R, Laurent C, Youwakim J, Paradis P, Arbour N, et al: CD4(+) Regulatory T Lymphocytes Prevent Impaired Cerebral Blood Flow in Angiotensin II-Induced Hypertension. J Am Heart Assoc2019, 8:e009372.

14. Lee DL, Sturgis LC, Labazi H, Osborne JB, Jr., Fleming C, Pollock JS, Manhiani M, Imig JD, Brands MW: Angiotensin II hypertension is attenuated in interleukin-6 knockout mice. Am J Physiol Heart Circ Physio/2006, 290:H935-940.

15. Zhang W, Wang W, Yu H, Zhang Y, Dai Y, Ning C, Tao L, Sun H, Kellems RE, Blackburn MR, Xia Y: Interleukin 6 underlies angiotensin II-induced hypertension and chronic renal damage. Hypertension2012, 59:136-144. 
16. Kimura A, Kishimoto T: IL-6: regulator of Treg/Th17 balance. Eur J Immuno/2010, 40:1830-1835.

17. Weaver CT, Harrington LE, Mangan PR, Gavrieli M, Murphy KM: Th17: an effector CD4 T cell lineage with regulatory T cell ties. Immunity2006, 24:677-688.

18. Devereux RB, Alonso DR, Lutas EM, Gottlieb GJ, Campo E, Sachs I, Reichek N: Echocardiographic assessment of left ventricular hypertrophy: comparison to necropsy findings. Am J Cardio/1986, 57:450458.

19. 2018 Chinese Guidelines for Prevention and Treatment of Hypertension-A report of the Revision Committee of Chinese Guidelines for Prevention and Treatment of Hypertension. J Geriatr Cardio/2019, 16:182-241.

20. Lang RM, Badano LP, Mor-Avi V, Afilalo J, Armstrong A, Ernande L, Flachskampf FA, Foster E, Goldstein SA, Kuznetsova T, et al: Recommendations for cardiac chamber quantification by echocardiography in adults: an update from the American Society of Echocardiography and the European Association of Cardiovascular Imaging. J Am Soc Echocardiogr2015, 28:1-39.e14.

21. Babiker FA, Lips D, Meyer R, Delvaux E, Zandberg P, Janssen B, van Eys G, Grohé C, Doevendans PA: Estrogen receptor beta protects the murine heart against left ventricular hypertrophy. Arterioscler Thromb Vasc Bio/2006, 26:1524-1530.

22. van Eickels M, Grohé C, Cleutjens JP, Janssen BJ, Wellens HJ, Doevendans PA: 17beta-estradiol attenuates the development of pressure-overload hypertrophy. Circulation2001, 104:1419-1423.

23. Patten RD, Pourati I, Aronovitz MJ, Alsheikh-Ali A, Eder S, Force T, Mendelsohn ME, Karas RH: 17 Betaestradiol differentially affects left ventricular and cardiomyocyte hypertrophy following myocardial infarction and pressure overload. J Card Fail2008, 14:245-253.

24. Palacios S, Henderson VW, Siseles N, Tan D, Villaseca P: Age of menopause and impact of climacteric symptoms by geographical region. Climacteric2010, 13:419-428.

25. Kassan M, Wecker A, Kadowitz $P$, Trebak M, Matrougui K: CD4+CD25+Foxp3 regulatory T cells and vascular dysfunction in hypertension. J Hypertens2013, 31:1939-1943.

26. Li M, Wang X, Fu W, He S, Li D, Ke Q: CD4+CD25+Foxp3+ regulatory T cells protect endothelial function impaired by oxidized low density lipoprotein via the KLF-2 transcription factor. Cell Physiol Biochem2011, 28:639-648.

27. Radwan E, Mali V, Haddox S, El-Noweihi A, Mandour M, Ren J, Belmadani S, Matrougui K: Treg cells depletion is a mechanism that drives microvascular dysfunction in mice with established hypertension. Biochim Biophys Acta Mol Basis Dis2019, 1865:403-412. 
28. Mian MO, Barhoumi T, Briet M, Paradis P, Schiffrin EL: Deficiency of T-regulatory cells exaggerates angiotensin II-induced microvascular injury by enhancing immune responses. $J$ Hypertens2016, 34:97108.

29. Barhoumi T, Kasal DA, Li MW, Shbat L, Laurant P, Neves MF, Paradis P, Schiffrin EL: T regulatory lymphocytes prevent angiotensin II-induced hypertension and vascular injury. Hypertension2011, 57:469476.

30. Trott DW, Thabet SR, Kirabo A, Saleh MA, Itani H, Norlander AE, Wu J, Goldstein A, Arendshorst WJ, Madhur MS, et al: Oligoclonal CD8+ T cells play a critical role in the development of hypertension. Hypertension2014, 64:1108-1115.

31. Kassan M, Galan M, Partyka M, Trebak M, Matrougui K: Interleukin-10 released by CD4(+)CD25(+) natural regulatory $T$ cells improves microvascular endothelial function through inhibition of NADPH oxidase activity in hypertensive mice. Arterioscler Thromb Vasc Bio/2011, 31:2534-2542.

32. Vignali DA, Collison LW, Workman CJ: How regulatory T cells work. Nat Rev Immuno/2008, 8:523-532.

33. Matrougui K, Abd Elmageed Z, Kassan M, Choi S, Nair D, Gonzalez-Villalobos RA, Chentoufi AA, Kadowitz P, Belmadani S, Partyka M: Natural regulatory T cells control coronary arteriolar endothelial dysfunction in hypertensive mice. Am J Patho/2011, 178:434-441.

34. Turner JA, Stephen-Victor E, Wang S, Rivas MN, Abdel-Gadir A, Harb H, Cui Y, Fanny M, Charbonnier LM, Fong JJH, et al: Regulatory T Cell-Derived TGF- $\beta 1$ Controls Multiple Checkpoints Governing Allergy and Autoimmunity. Immunity2020, 53:1202-1214.e1206.

35. Haribhai D, Williams JB, Jia S, Nickerson D, Schmitt EG, Edwards B, Ziegelbauer J, Yassai M, Li SH, Relland $L M$, et al: A requisite role for induced regulatory $\mathrm{T}$ cells in tolerance based on expanding antigen receptor diversity. Immunity2011, 35:109-122.

36. Marie JC, Letterio JJ, Gavin M, Rudensky AY: TGF-beta1 maintains suppressor function and Foxp3 expression in CD4+CD25+ regulatory T cells. J Exp Med2005, 201:1061-1067.

37. Saraiva M, Vieira P, O'Garra A: Biology and therapeutic potential of interleukin-10. J Exp Med2020, 217.

38. Tang TT, Yuan J, Zhu ZF, Zhang WC, Xiao H, Xia N, Yan XX, Nie SF, Liu J, Zhou SF, et al: Regulatory T cells ameliorate cardiac remodeling after myocardial infarction. Basic Res Cardio/2012, 107:232.

39. Lai NC, Gao MH, Tang E, Tang R, Guo T, Dalton ND, Deng A, Tang T: Pressure overload-induced cardiac remodeling and dysfunction in the absence of interleukin 6 in mice. Lab Invest2012, 92:15181526. 
40. Chen F, Chen D, Zhang Y, Jin L, Zhang H, Wan M, Pan T, Wang X, Su Y, Xu Y, Ye J: Interleukin-6 deficiency attenuates angiotensin II-induced cardiac pathogenesis with increased myocyte hypertrophy. Biochem Biophys Res Commun2017, 494:534-541.

41. Brands MW, Banes-Berceli AK, Inscho EW, Al-Azawi H, Allen AJ, Labazi H: Interleukin 6 knockout prevents angiotensin II hypertension: role of renal vasoconstriction and janus kinase $2 /$ signal transducer and activator of transcription 3 activation. Hypertension2010, 56:879-884.

42. Zhao L, Cheng G, Jin R, Afzal MR, Samanta A, Xuan YT, Girgis M, Elias HK, Zhu Y, Davani A, et al: Deletion of Interleukin-6 Attenuates Pressure Overload-Induced Left Ventricular Hypertrophy and Dysfunction. Circ Res2016, 118:1918-1929.

43. Shi W, Ma H, Liu T, Yan D, Luo P, Zhai M, Tao J, Huo S, Guo J, Li C, et al: Inhibition of Interleukin6/glycoprotein 130 signalling by Bazedoxifene ameliorates cardiac remodelling in pressure overload mice. 2020, 24:4748-4761.

44. Assadi F: C-reactive protein and incident left ventricular hypertrophy in essential hypertension. Pediatr Cardio/2007, 28:280-285.

45. Monfared A, Salari A, Kazemnezhad E, Lebadi M, Khosravi M, Mehrjardi NK, Rahimifar S, Amini N: Association of left ventricular hypertrophy with high-sensitive C-reactive protein in hemodialysis patients. Int Urol Nephro/2013, 45:1679-1686.

46. Vaĭda LS, Lozyns'ka NV: [The relation of structural and functional status of the left chambers of the heart, the level of circulating NT-pro-BNP and the status of endothelium dependent vasodilation with characteristics of $\mathbf{2 4}$ hour blood pressure monitoring in patients with arterial hypertension]. Lik Sprava2013:16-24.

47. Ojji DB, Opie LH, Lecour S, Lacerda L, Adeyemi OM, Sliwa K: The proposed role of plasma NT probrain natriuretic peptide in assessing cardiac remodelling in hypertensive African subjects. Cardiovasc $J$ Afr2014, 25:233-238.

48. Jiang T, Zhao Q: Scolopendra subspinipes mutilans L. Koch Ameliorates Rheumatic Heart Disease by Affecting Relative Percentages of CD4(+)CD25(+)FoxP3 Treg and CD4(+)IL17 T Cells. 2019, 2019:4674190.

49. Jin Y, Xu H, Wu M, Yi B, Zhu M, Zhou Y, Wang J: Correlation of gestational hypertension with abnormal lipid metabolism, insulin resistance and D-dimer and their clinical significance. Exp Ther Med2019, 17:1346-1350.

50. Zicha J, Kunes J, Devynck MA: Abnormalities of membrane function and lipid metabolism in hypertension: a review. Am J Hypertens1999, 12:315-331. 
51. Trpkovic A, Resanovic I, Stanimirovic J, Radak D, Mousa SA, Cenic-Milosevic D, Jevremovic D, Isenovic ER: Oxidized low-density lipoprotein as a biomarker of cardiovascular diseases. Crit Rev Clin Lab Sci2015, 52:70-85.

52. Li Q, Wang Y, Wang Y, Zhou Q, Chen K, Wang YM, Wei W, Wang Y: Distinct different sensitivity of Treg and Th17 cells to Fas-mediated apoptosis signaling in patients with acute coronary syndrome. Int J Clin Exp Patho/2013, 6:297-307.

53. Li Q, Wang Y, Li H, Shen G, Hu S: Ox-LDL influences peripheral Th17/Treg balance by modulating Treg apoptosis and Th17 proliferation in atherosclerotic cerebral infarction. Cell Physiol Biochem2014, 33:1849-1862.

54. Wagner NM, Brandhorst G, Czepluch F, Lankeit M, Eberle C, Herzberg S, Faustin V, Riggert J, Oellerich $M$, Hasenfuss $G$, et al: Circulating regulatory $T$ cells are reduced in obesity and may identify subjects at increased metabolic and cardiovascular risk. Obesity (Silver Spring)2013, 21:461-468.

55. Tackling G, Borhade MB: Hypertensive Heart Disease. In StatPearls. Treasure Island (FL): StatPearls Publishing Copyright (c) 2021, StatPearls Publishing LLC.; 2021

\section{Figures}



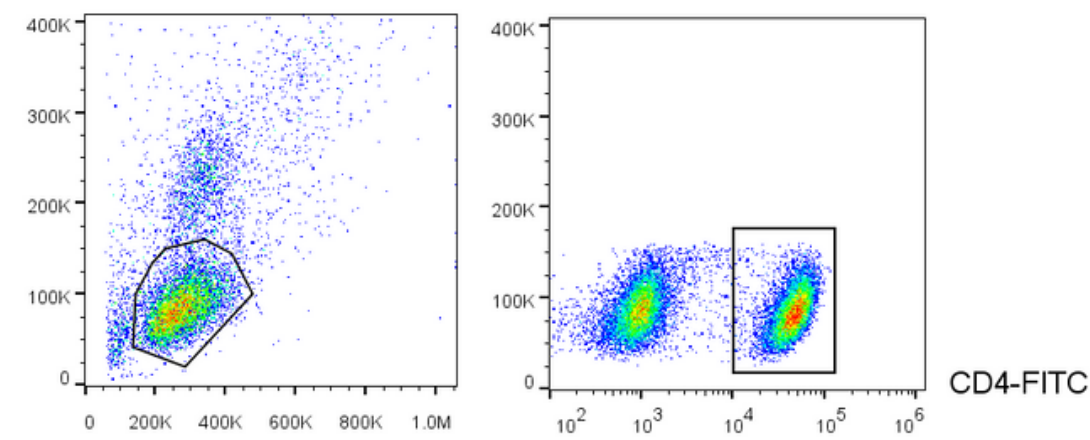

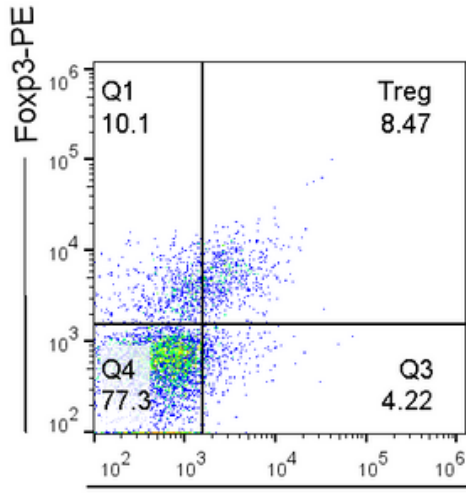

CG

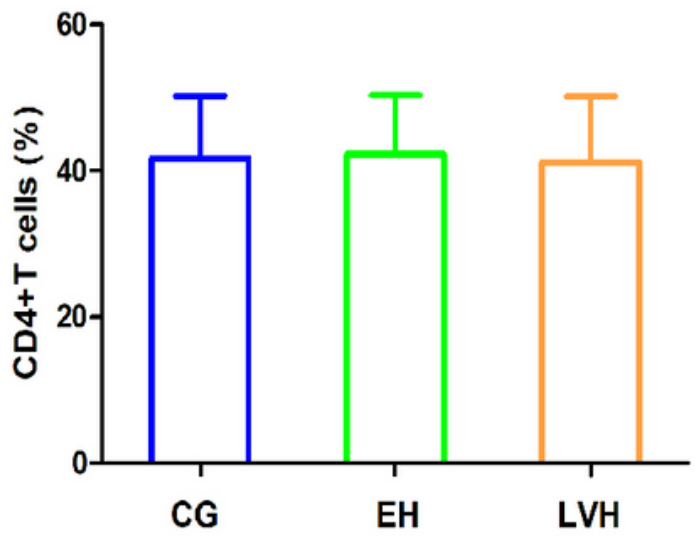

(b)

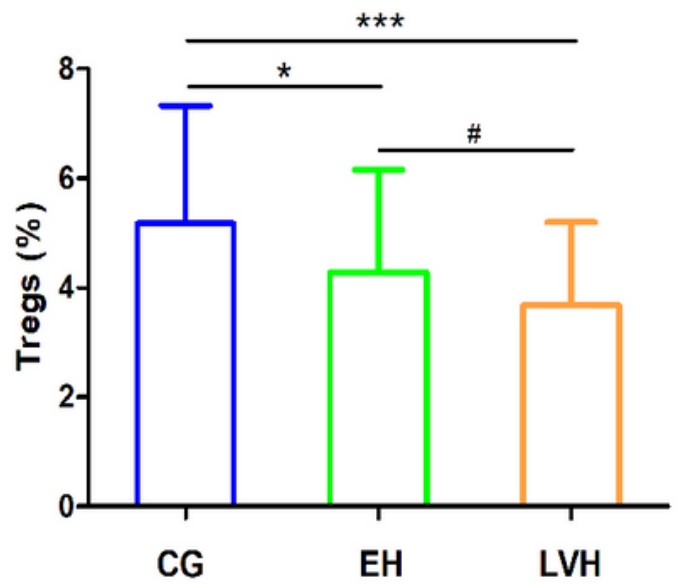

(c)

Figure 1

Circulating CD4+ T cells and Tregs in CG, EH and LVH patients. 


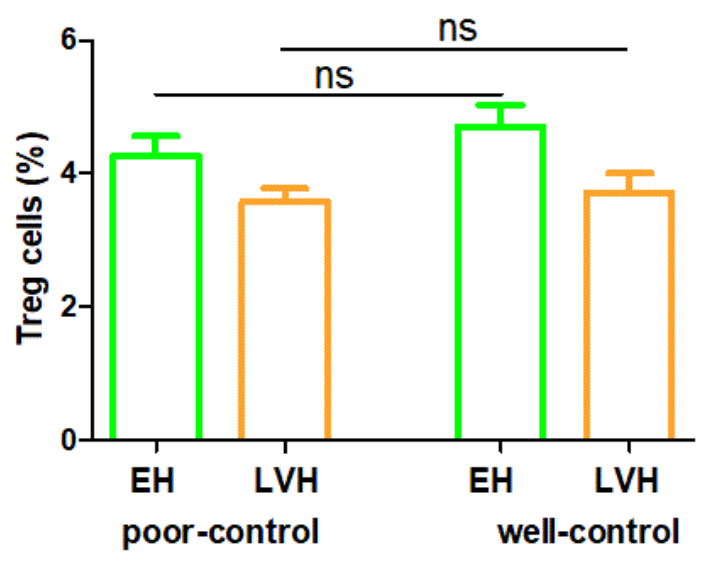

(a)

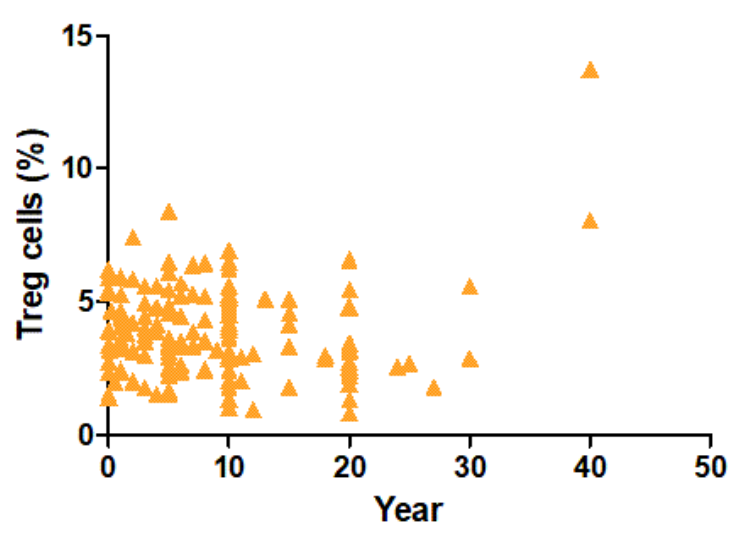

(b)

Figure 2

Circulating Tregs and blood pressure control in hypertensive patients.

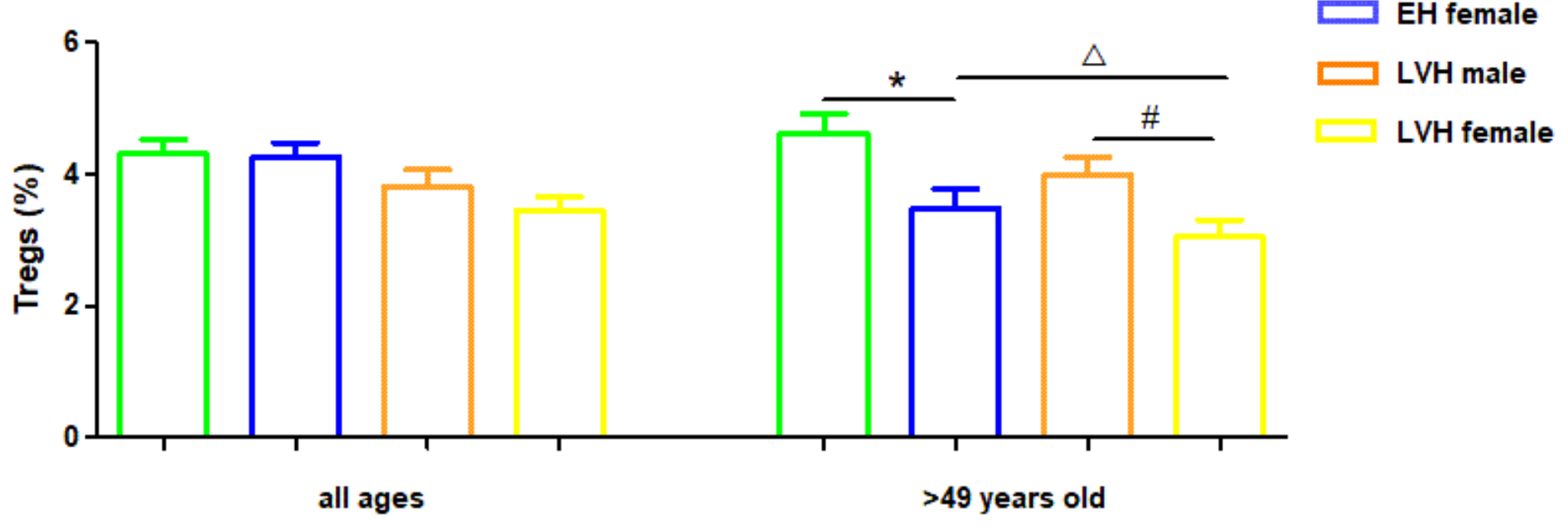

Figure 3

Sex difference of circulating Tregs in EH and LVH patients. 


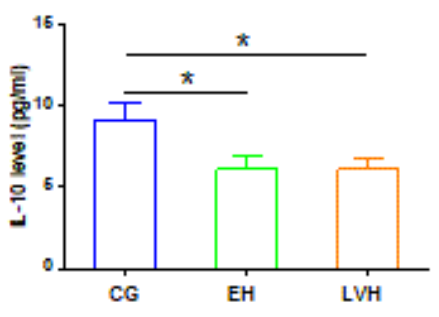

(a)
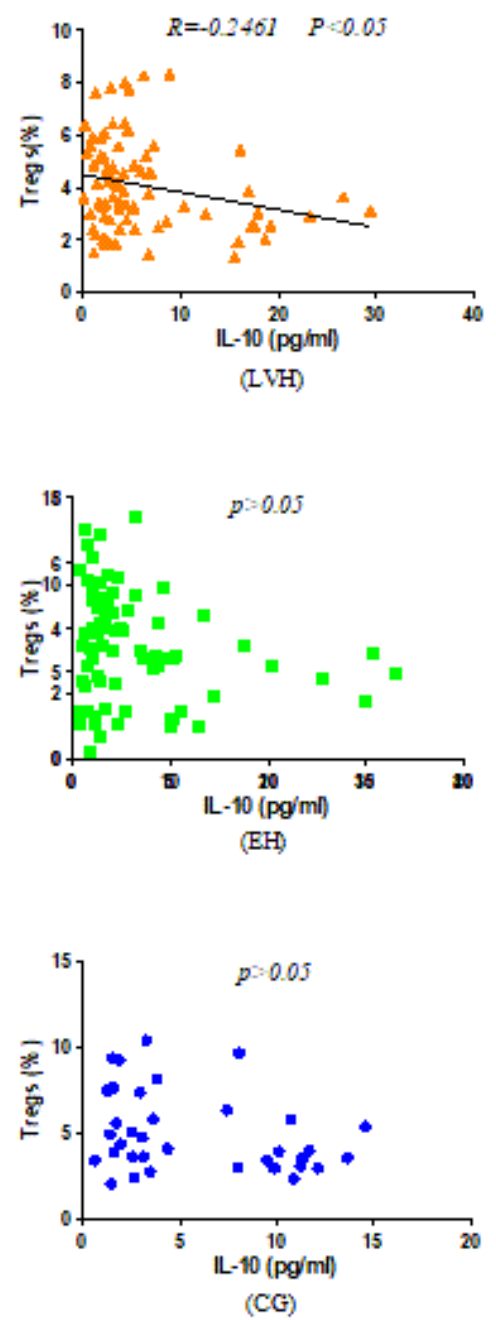

(d)

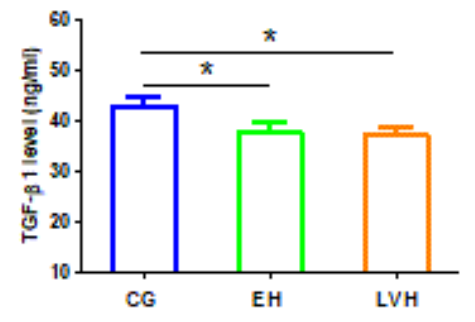

(b)
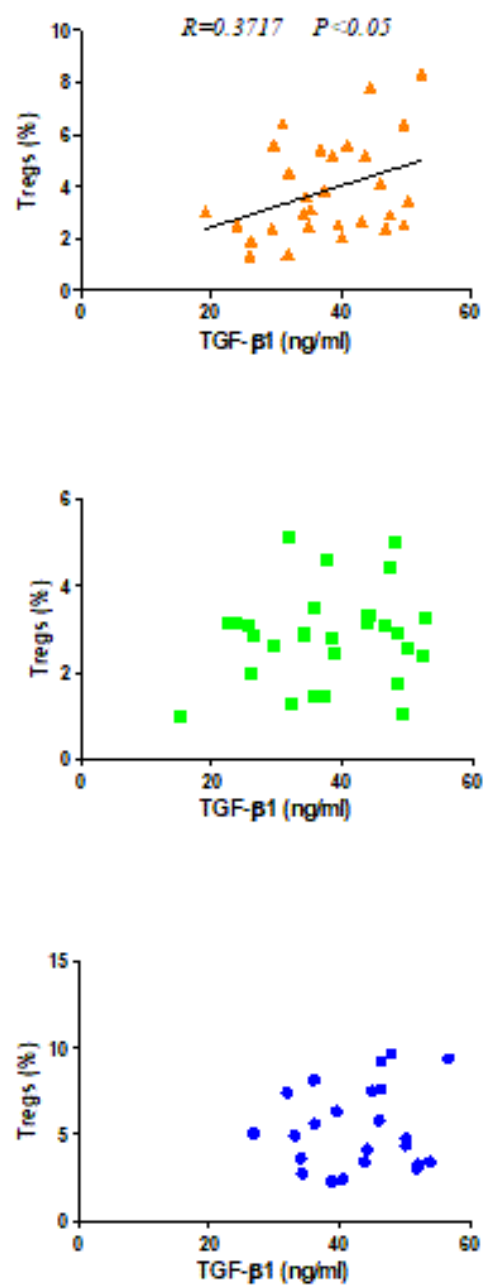

(e)

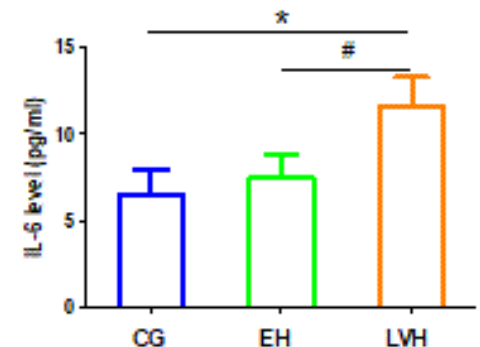

(c)
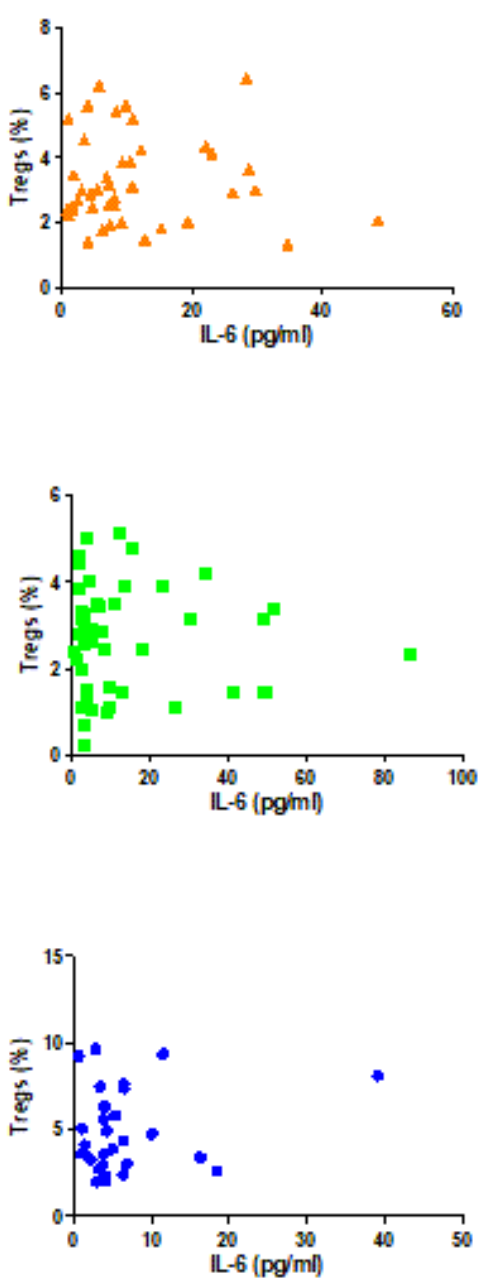

\section{Figure 4}

Serum cytokine levels in each group. 


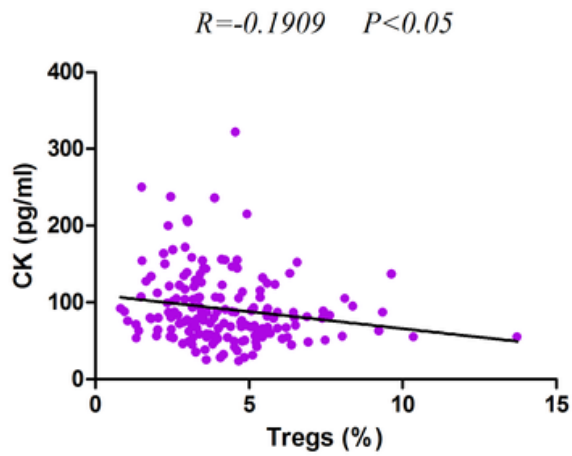

(a)

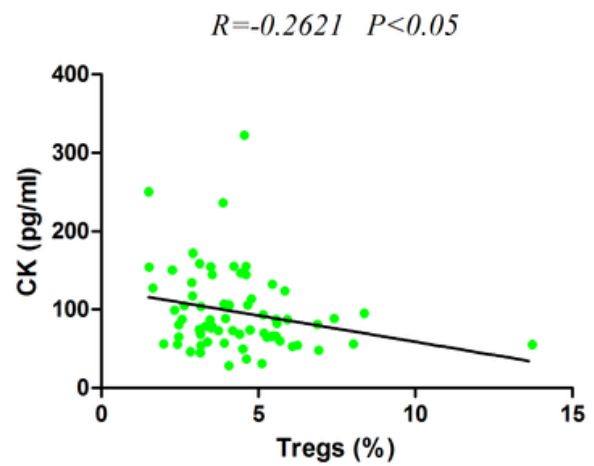

(d)

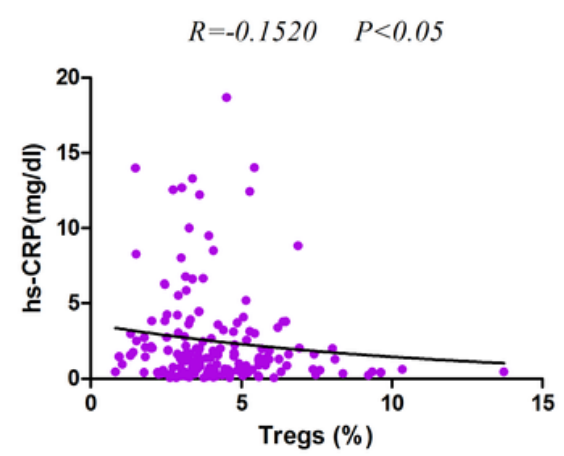

(b)

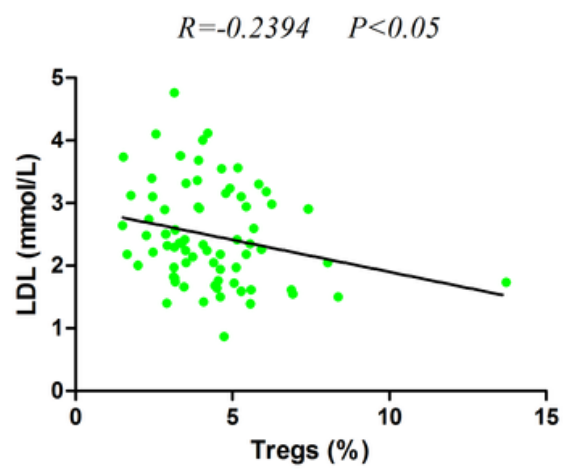

(e)

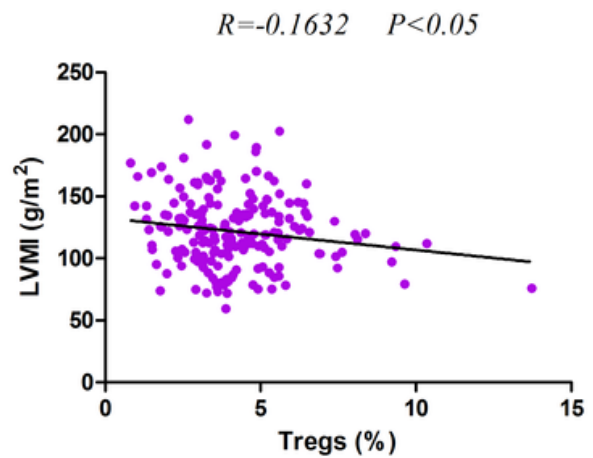

(c)

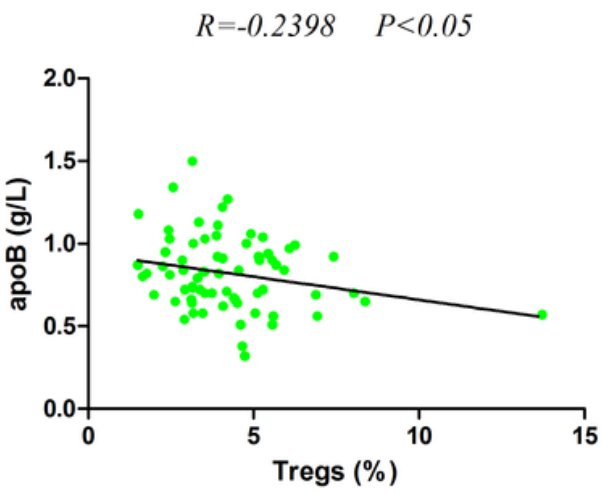

(f)

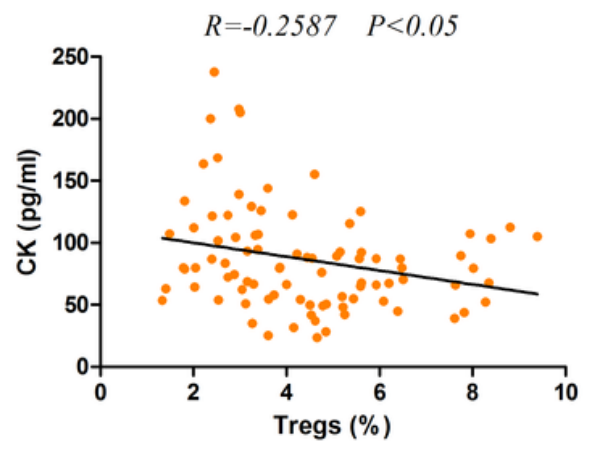

(g)

\section{Figure 5}

The correlation of Tregs and clinical characteristics in patients. 